\title{
Coulomb lifetime of the ring current ions with time varying plasmasphere
}

\author{
Yusuke Ebihara $^{1}$, Masaki Ejiri² ${ }^{2}$ and Hiroshi Miyaoka ${ }^{2}$ \\ ${ }^{1}$ Department of Polar Science, The Graduate University for Advanced Studies, Tokyo, Japan \\ ${ }^{2}$ National Institute of Polar Research, Tokyo, Japan
}

(Received June 30, 1997; Revised March 20, 1998; Accepted March 27, 1998)

\begin{abstract}
We have developed a time-dependent model of the plasmasphere to evaluate the spatial variation of the Coulomb lifetime of ring current ions. Coulomb collision has been considered to be one of major loss processes of the ring current ions interacted with the thermal plasma in the plasmasphere. The distribution of plasmaspheric density is derived by a continuity equation under the hydrostatic assumption. The protons supplied from both conjugate ionospheres are drifted by a time-dependent convection field and a corotation electric field. Calculated profiles of the number density and the relative motion of the plasmasphere are in fairly good agreement with the observational results by EXOS-B satellite. We traced the energetic ions during a storm on June 4-8, 1991 and calculated the differential flux and the pressure to examine the loss effects on the pressure due to the both loss processes. We found that (1) the Coulomb collision loss restrictively affects at $L \leq 3$ because the plasmasphere drastically shrank due to the strong convection, and that (2) there is no significant change in the ion composition ratio during the initial rapid recovery of $D s t$, i.e., the rapid recovery of $D s t$ is not caused by the short charge exchange lifetime of $\mathrm{O}^{+}$ions for this particular storm.
\end{abstract}

\section{Introduction}

The dominant loss processes of the ring current energetic ions have been considered to be charge exchange with neutral atoms (e.g., Dessler and Parker, 1959; Smith et al., 1976) and the Coulomb collision with dense cold plasmas in the plasmasphere (e.g., Wentworth et al., 1959; Liemohn, 1961; Kistler et al., 1989; Fok et al., 1991). The number densities of the above scattering particles are required when we consider the lifetimes of the charge exchange and Coulomb collision losses. Though the distribution of neutral atoms is relatively steady, the distribution of plasmaspheric cold plasmas is changed with the magnetospheric activity. Therefore the time-varying distribution of the plasmasphere is important to evaluate the Coulomb lifetime of the ring current ions and to discuss the ring current formation as well. In this paper, we develop a new model of the time-varying plasmasphere, and we examine the time-dependent spatial distribution of the Coulomb lifetime of the energetic ions $\left(\mathrm{H}^{+}, \mathrm{He}^{+}\right.$ and $\mathrm{O}^{+}$) and charge exchange lifetime.

The plasmasphere is formed by the bulk motion of the cold plasmasphere in the magnetosphere (e.g., Nishida, 1966; Brice, 1967). Many authors have discussed the deformation of the plasmapause or detachment of plasmatail (e.g., Carpenter, 1966; Chappell et al., 1970; Chen and Wolf, 1972; Grebowsky et al., 1974; Grebowsky and Chen, 1975; Maynard and Chen, 1975; Horwitz et al., 1990; Gallagher et al., 1995; Moldwin et al., 1995). Since ionospheric thermal plasma can escape and can form the plasmasphere, the coupling between ionosphere and plasmasphere is important through a refilling process. Many kinds of large-scale refill-

Copy right $(\mathrm{C}$ The Society of Geomagnetism and Earth, Planetary and Space Sciences (SGEPSS); The Seismological Society of Japan; The Volcanological Society of Japan; The Geodetic Society of Japan; The Japanese Society for Planetary Sciences. ing models have been proposed, for example, hydrodynamic models (e.g., Mayr et al., 1970; Moffett and Murphy, 1973; Marubashi and Grebowsky, 1976; Li et al., 1983; Khazanov et al., 1984; Singh and Chan, 1992; Guiter et al., 1995) and semikinetic models (e.g., Lin et al., 1992; Wilson et al., 1992). However we applied the total ion contents model described in Chen and Wolf (1972) for modeling the transport of ionospheric plasmas into a flux tube. By solving a differential equation as mentioned below, we calculate the saturation density and refilling time constant of the plasmasphere, that is, the empirical model is not introduced (Carpenter and Anderson, 1992; Rasmussen et al., 1993). Unless otherwise mentioned MKS unit is used throughout this paper.

\section{Three-Dimensional Model of the Plasmasphere 2.1 Ionosphere-magnetosphere coupling}

The $\mathrm{H}^{+}$ions supplying to the plasmasphere are mainly produced by charge exchange reaction in the conjugate ionospheres, i.e.,

$$
\mathrm{O}^{+}+\mathrm{H} \rightarrow \mathrm{O}+\mathrm{H}^{+}
$$

The reverse reaction can occur easily because the ionized potentials of $\mathrm{H}^{+}$and $\mathrm{O}^{+}$are very closed to each other. Therefore the main sink of the $\mathrm{H}^{+}$ions is the reactions of

$$
\mathrm{H}^{+}+\mathrm{O} \rightarrow \mathrm{H}+\mathrm{O}^{+}
$$

The continuity equation along a flux tube is

$$
\frac{\partial F}{\partial s}=P_{\mathrm{H}^{+}}-L_{\mathrm{H}^{+}},
$$

where $F$ is the $\mathrm{H}^{+}$flux, $s$ the distance along a field line, $P_{\mathrm{H}^{+}}$a production rate of $\mathrm{H}^{+}$and $L_{\mathrm{H}^{+}}$a loss rate of $\mathrm{H}^{+}$. The production and loss rates, $P_{\mathrm{H}^{+}}$and $L_{\mathrm{H}^{+}}$, are (Banks and 


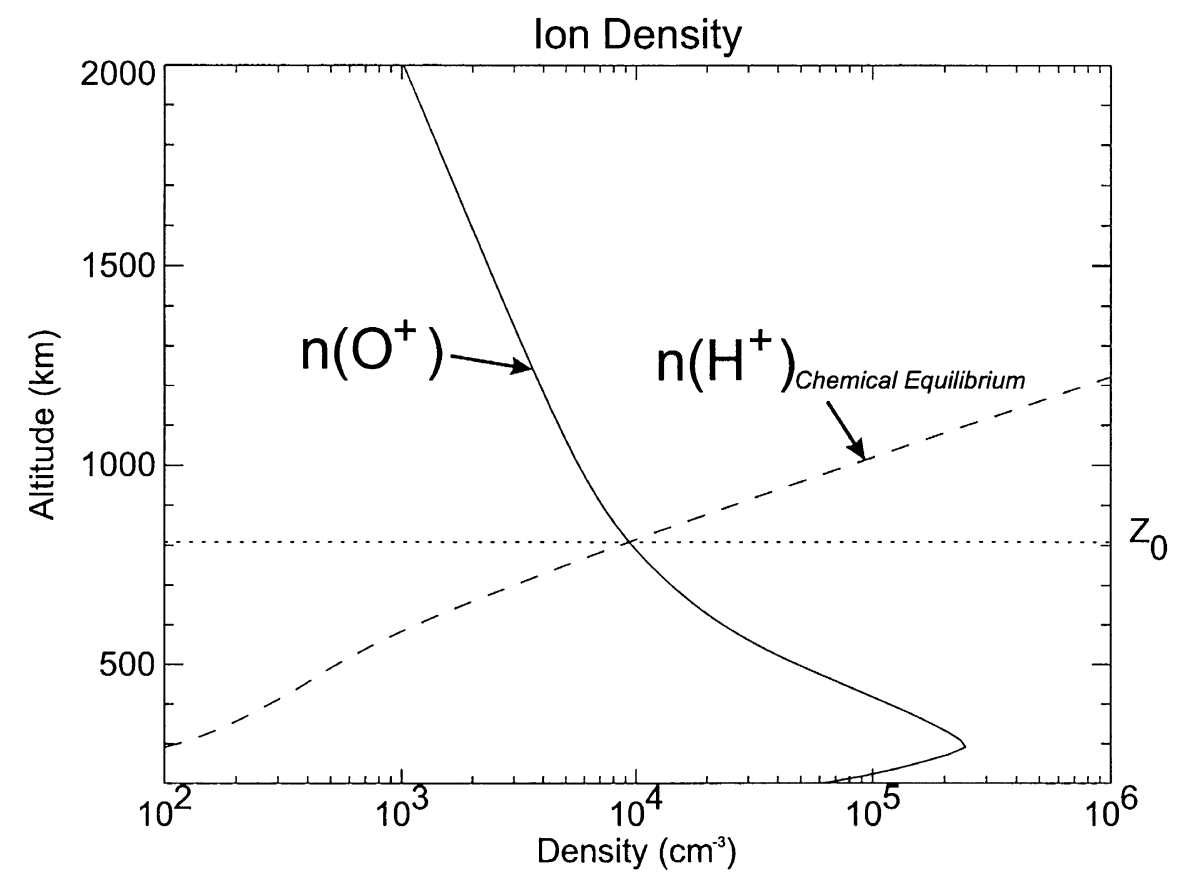

Fig. 1. Typical profiles of $\mathrm{O}^{+}$density $n\left(\mathrm{O}^{+}\right)$(solid line) and the chemical equilibrium $\mathrm{H}^{+}$density $n\left(\mathrm{H}^{+}\right)($dashed line) at noon during summer.

Kocharts, 1973),

$$
\begin{aligned}
& P_{\mathrm{H}}=.5 \times 10^{-17} T_{\mathrm{n}}^{1 / 2} n(\mathrm{H}) n\left(\mathrm{O}^{+}\right)\left[1 / \mathrm{m}^{3} \mathrm{~s}\right], \\
& L_{\mathrm{H}}=.2 \times 10^{-17} T_{\mathrm{i}}^{1 / 2} n(\mathrm{O}) n\left(\mathrm{H}^{+}\right)\left[1 / \mathrm{m}^{3} \mathrm{~s}\right],
\end{aligned}
$$

where $n(\mathrm{H}), n(\mathrm{O}), n\left(\mathrm{H}^{+}\right), n\left(\mathrm{O}^{+}\right), T_{\mathrm{i}}$ and $T_{\mathrm{n}}$ are densities of neutral hydrogen, neutral oxygen, proton, oxygen ion, and ion and neutral temperatures, respectively. Integrating Eq. (2) along a field line, the upward flux becomes

$$
F(s)=F_{0} \frac{B(s)}{B_{0}}+B_{0} \int_{0}^{s}\left(P_{\mathrm{H}^{+}}-L_{\mathrm{H}^{+}}\right) \frac{d s}{B(s)}\left[1 / \mathrm{m}^{2} \mathrm{~s}\right],
$$

where $B$ is a magnetic intensity, and $s$ is the distance along a field line. The subscript 0 refers to the lower boundary altitude $z_{0}$ of the production/loss region. The upward flux will be maximum when the plasmasphere is depleted after a large magnetic storm. In this situation, $L_{\mathrm{H}^{+}}=0$, the upward flux becomes maximum and the maximum flux is called as a limiting flux.

The chemical equilibrium is the state that production and loss rates are equal. The concentration of chemical equilibrium $\mathrm{H}^{+}$ions in the ionosphere is derived from an equality of $P_{\mathrm{H}^{+}}$and $L_{\mathrm{H}^{+}}$, i.e.,

$$
n\left(\mathrm{H}^{+}\right)=\frac{2.5 \times 10^{-17} T_{\mathrm{n}}^{1 / 2} n(\mathrm{H})}{2.2 \times 10^{-17} T_{\mathrm{i}}^{1 / 2} n(\mathrm{O})} n\left(\mathrm{O}^{+}\right)\left[1 / \mathrm{m}^{3}\right] .
$$

The typical profiles of $\mathrm{O}^{+}$density and chemical equilibrium $\mathrm{H}^{+}$density are shown in Fig. 1. The IRI-95 (Bilitza, 1986) and MSISE-90 (Hedin, 1987, 1991) models are used to calculate these ionospheric and thermospheric quantities. The lower boundary $z_{0}$ is the altitude where $\mathrm{H}^{+}$density is equal to $\mathrm{O}^{+}$density in Fig. 1. In other words, the bulk motion of the plasma due to the ambipolar diffusion is controlled by $\mathrm{H}^{+}$in the region above $z_{0}$. The lower boundary altitude is highly sensitive to the solar activity as shown in Fig. 2. The lower boundary in the solar minimum is from $600 \mathrm{~km}$ to $800 \mathrm{~km}$ depending its local time and latitude, but in the solar maximum (the bottom panel of Fig. 2), the altitudes is roughly twice the altitude in solar minimum (the top panel of Fig. 2). When solar activity is high, O density is increased, then chemical equilibrium $\mathrm{H}^{+}$density is increased and the lower boundary $z_{0}$ becomes a higher altitude.

Since $n\left(\mathrm{O}^{+}\right)$profile falls off exponentially with altitude, $\mathrm{H}^{+}$that escapes to the plasmasphere is produced within one scale height of $\mathrm{O}^{+}$(Raitt et al., 1975), and the loss region of $\mathrm{H}^{+}$ions may exist within one scale height of atomic oxygen above $z_{0}$. Then, we obtain the flux which can escape to the plasmasphere as,

$$
F(s)=P_{\mathrm{H}^{+}} H\left(\mathrm{O}^{+}\right)-L_{\mathrm{H}^{+}} H(\mathrm{O})\left[1 / \mathrm{m}^{2} \mathrm{~s}\right],
$$

where $H\left(\mathrm{O}^{+}\right)$is the scale height of $\mathrm{O}^{+}$and $H(\mathrm{O})$ the scale height of atomic oxygen at the lower boundary $z_{0}$.

The continuity equation of the total ion content per unit magnetic flux $N$ is

$$
\frac{d N}{d t}=\frac{F_{\mathrm{N}}+F_{\mathrm{S}}}{B_{0}}
$$

where $B_{0}$ is the magnetic intensity at the ionosphere, and $N$ is defined as

$$
N=\int \frac{n h_{\mathrm{s}}}{B} d s[1 / \mathrm{Wb}]
$$

where $h_{\mathrm{s}}$ is the coordinate scale factor aligned with a field line. The subscripts $\mathrm{N}$ and $\mathrm{S}$ represent northern and southern hemispheres, respectively. The average density in a flux tube $\bar{n}$ is

$$
\bar{n}=\frac{N}{V}\left[1 / \mathrm{m}^{3}\right]
$$


(a) Solar Minimum

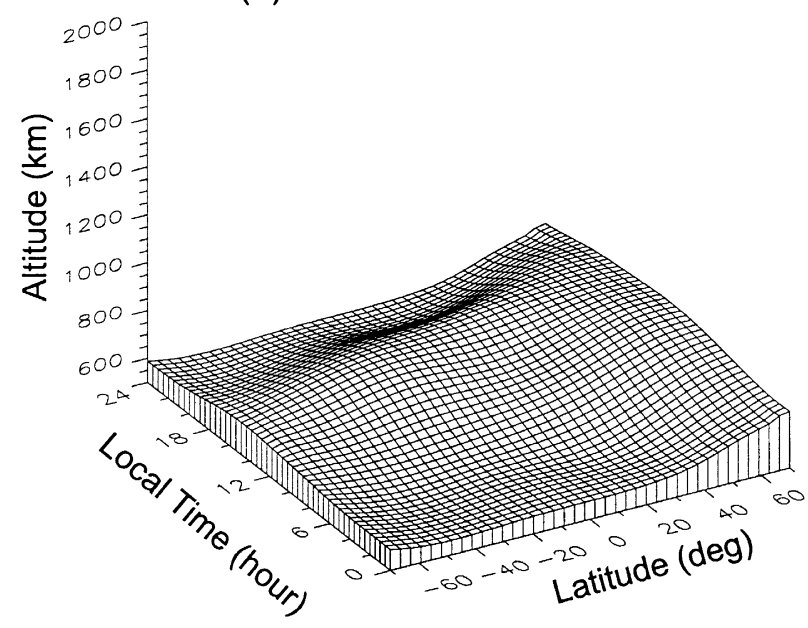

(b) Solar Maximum

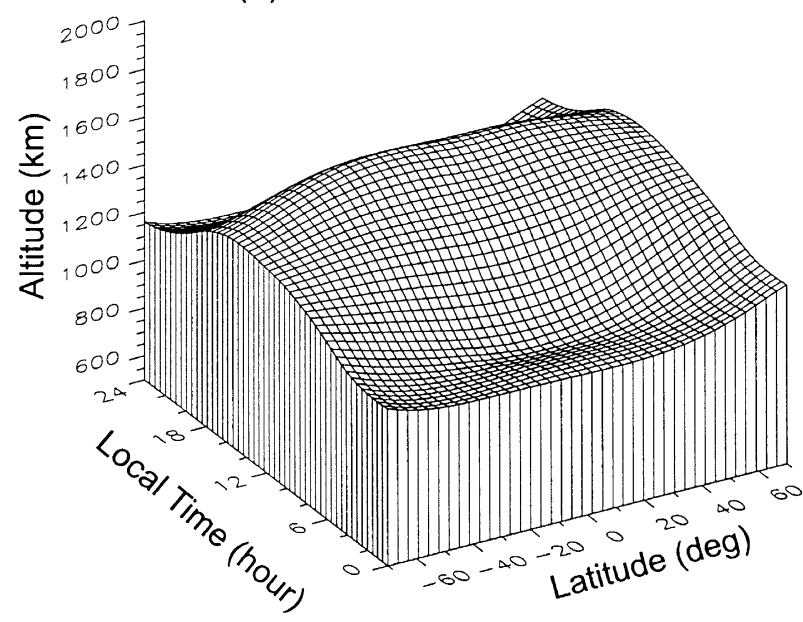

Fig. 2. The latitudinal and longitudinal variation of the lower boundary altitude $z_{0}$ for (a) a solar minimum and (b) a solar maximum.

where

$$
V=\int h_{\mathrm{s}} B d s\left[\mathrm{~m}^{3} / \mathrm{Wb}\right]
$$

The continuity equation of the average density becomes,

$$
\frac{d \bar{n}}{d t}=\frac{F_{\mathrm{N}}+F_{\mathrm{S}}}{B_{0} V}\left[1 / \mathrm{m}^{3} \mathrm{~s}\right] .
$$

A relation between $\mathrm{H}^{+}$density at the conjugate ionosphere $n_{0}$ and average density $\bar{n}$ is required to solve Eq. (12). We assume that the variation of number density along a field line is in hydrostatic equilibrium which is derived from plasma transport equation (e.g., Eq. (15) of Rasmussen et al., 1993) by the following assumptions; (1) pressure is isotropic, (2) temperatures are constant and (3) inertia force is negligible. The distribution in the hydrostatic equilibrium state with the dipole field as a function of colatitude $\theta$ is

$$
n(\theta)=n_{0} \exp \left\{\frac{R e}{H_{0}^{*} L}\left(\frac{1}{\sin ^{2} \theta}-\frac{1}{\sin ^{2} \theta_{0}}\right)\right\},
$$

and

$$
H_{0}^{*}=\frac{k\left(T_{\mathrm{i}}+T_{\mathrm{e}}\right)}{m g_{0}},
$$

where $g_{0}, k, m, n_{0}, T_{\mathrm{e}}, T_{\mathrm{i}}$ and $\theta_{0}$ are gravity force at surface of the Earth, Boltzmann's constant, mass of $\mathrm{H}^{+}, \mathrm{H}^{+}$density at the altitude of $z_{0}$, electron temperature, ion temperature, and colatitude of the production/loss region in the conjugate ionosphere, respectively. The colatitude $\theta_{0}$ is

$$
\sin ^{2} \theta_{0}=\frac{R e+z_{0}}{L R e},
$$

where $L$ and $R e$ are McIlwain's $L$-value and the Earth's radius. Especially, the equatorial density $n_{\text {eq }}$ is simply given by

$$
n_{\mathrm{eq}}=n_{0} \exp \left\{-\frac{R e}{H_{0}^{*} L \tan ^{2} \theta_{0}}\right\} .
$$

From Eqs. (10) and (13), the average density $\bar{n}$ is analytically given by

$$
\bar{n}=n_{0} Q
$$

where

$$
Q \equiv \frac{\int_{\pi / 2}^{\theta_{0}} \sin ^{7} \theta \exp \left\{\frac{R e}{H_{0}^{*} L}\left(\frac{1}{\sin ^{2} \theta}-\frac{1}{\sin ^{2} \theta_{0}}\right)\right\} d \theta}{\int_{\pi / 2}^{\theta_{0}} \sin ^{7} \theta d \theta} .
$$

Finally the differential equation of the average density becomes,

$$
\begin{aligned}
\frac{d \bar{n}}{d t \bar{t}}=\frac{1}{B_{0} V}\left\{\sum_{h=\mathrm{N}, \mathrm{S}} 2.5 \times 10^{-17} T_{\mathrm{n}, h}^{1 / 2} n_{h}(\mathrm{H}) n_{h}\left(\mathrm{O}^{+}\right) H_{h}\left(\mathrm{O}^{+}\right)\right. \\
\left.-\frac{\bar{n}}{Q} \sum_{h=\mathrm{N}, \mathrm{S}} 2.2 \times 10^{-17} T_{\mathrm{i}, h}^{1 / 2} n_{h}(\mathrm{O}) H_{h}(\mathrm{O})\right\}
\end{aligned}
$$

The solution of Eq. (19) clearly has a time constant $\tau$, so called refilling time constant,

$$
\tau=\frac{B_{0} V Q}{\sum_{h=\mathrm{N}, \mathrm{S}}\left(2.2 \times 10^{-17} T_{\mathrm{i}, h}^{1 / 2} n_{h}(\mathrm{O}) H_{h}(\mathrm{O})\right)},
$$

and has the saturation density $\bar{n}_{\text {sat }}$,

$$
\bar{n}_{\mathrm{sat}}=\frac{Q \sum_{h=\mathrm{N}, \mathrm{S}} 2.5 \times 10^{-17} T_{\mathrm{n}, h}^{1 / 2} n_{h}(\mathrm{H}) n_{h}\left(\mathrm{O}^{+}\right) H_{h}\left(\mathrm{O}^{+}\right)}{\sum_{h=\mathrm{N}, \mathrm{S}} 2.2 \times 10^{-17} T_{\mathrm{i}, h}^{1 / 2} n_{h}(\mathrm{O}) H_{h}(\mathrm{O})} .
$$

\subsection{Formation of the plasmasphere}

Since plasmaspheric ions are cold with temperature of $\sim 1 \mathrm{eV}$ (e.g., Olsen et al., 1987), the drift motion of the ions is determined by the $E \times B$ drift. We assume that the Earth's magnetic field is a dipole and the electric fields are composed of Volland-Stern type (Volland, 1973; Stern, 1975) convection field and the corotation field. The Volland-Stern model represents the convection field in the equatorial plane by the electric potential $\Phi$, i.e.,

$$
\Phi=A R^{\gamma} \sin \phi,
$$

where $R$ is a radial distance from the center of the Earth, $\phi$ a magnetic local time, $\gamma$ a shielding factor, and $A$ is given by Maynard and Chen (1975) as,

$$
A=\frac{0.045}{\left(1-0.159 K p+0.0093 K p^{2}\right)^{3}}\left[\mathrm{kV} / \mathrm{Re}^{2}\right]
$$



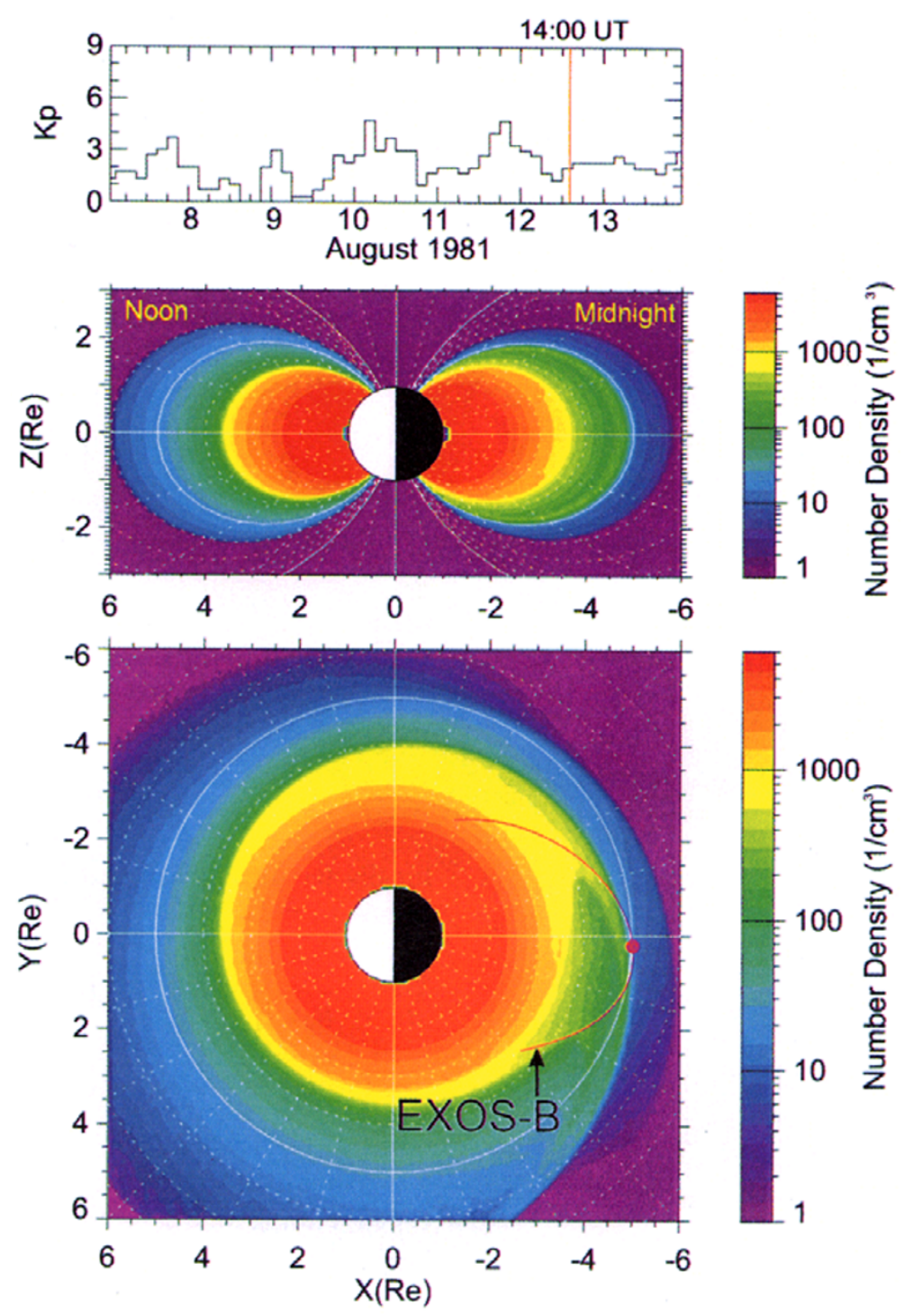

August 12, 1981 14:00 UT

Fig. 3. A snapshot of calculated number density of the plasmaspheric protons in the noon midnight meridian plane (middle) and in the equatorial plane (bottom) at 1400 UT of August 12, 1981. A purple line represents the trajectory of EXOS-B and a dot indicates the satellite's position at 1400 UT. The $K p$ indices are shown in the top of the panels.

We use $\gamma=2$ here.

\subsection{Comparison with satellite observation}

The Japanese satellite EXOS-B (JIKIKEN) was launched on September 16, 1979 into an equatorial orbit (the apogee of $5.1 \mathrm{Re}$, the height of perigee of $225 \mathrm{~km}$ and the inclination of $31^{\circ}$ ). Because of the low inclination orbit, EXOS-B could sweep widely from the ionosphere to beyond the plasmapause in the near equatorial plane. An electron density is directly calculated from an upper hybrid resonance frequency which is measured by a frequency swept impedance probe (IPS) (Ejiri et al., 1981) aboard EXOS-B using a length of $33.4 \mathrm{~m}$ antenna, a frequency range being from $10 \mathrm{kHz}$ to $3 \mathrm{MHz}$ with a swept period of $2 \mathrm{sec}$ (high bit rate) or $8 \mathrm{sec}$ (low bit rate).

We used three days of EXOS-B data from August 11-13, 1981, when EXOS-B had an apogee of near midnight. One of the orbits of EXOS-B on August 12, 1981 projected on the equatorial plane is shown in Fig. 3 with a snapshot of a contour map of the calculated proton number density. The orbit (purple line) passages from the dusk side to the dawn side through an apogee of $L=5.1$. A marked dot on the orbit path represents the position of EXOS-B at 1400 UT. At this time, a bulge of the plasmasphere is seen in near midnight, and the bulge is corotated with the Earth: the convection field intensity was decreasing since 2100 UT in the previous day.

The three days' profiles of the electron density observed by EXOS-B along their trajectories and profiles of the proton density calculated by this numerical model are shown in Fig. 4. We assume here that the number density of electrons is equal to the number density of protons.

In the first orbit (August 11, 1981; top panels of Fig. 4), EXOS-B experienced an enhancement of the convection 
August 11, 1981 13:04-18:10 UT
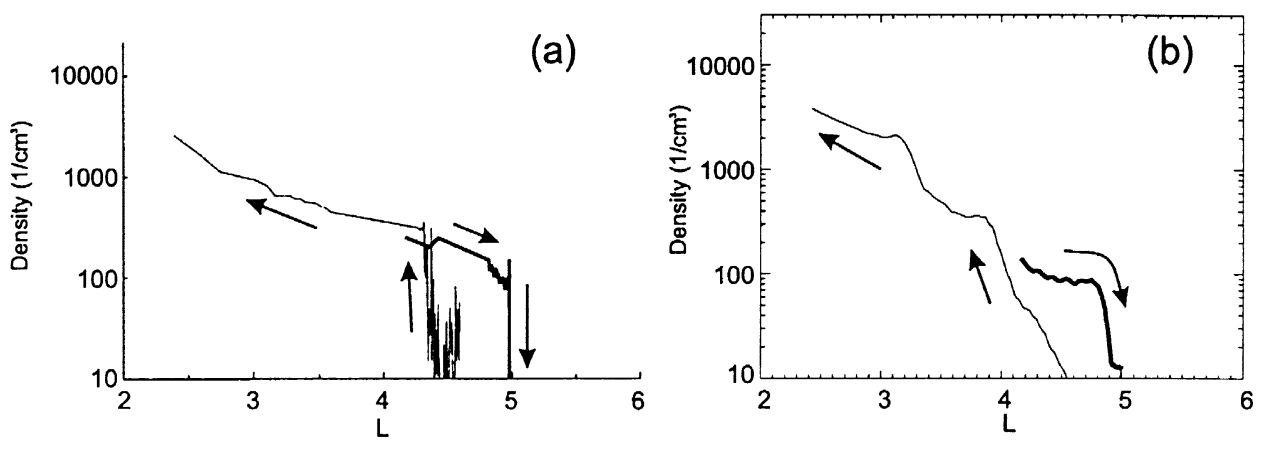

August 12, 1981 10:58-16:32 UT
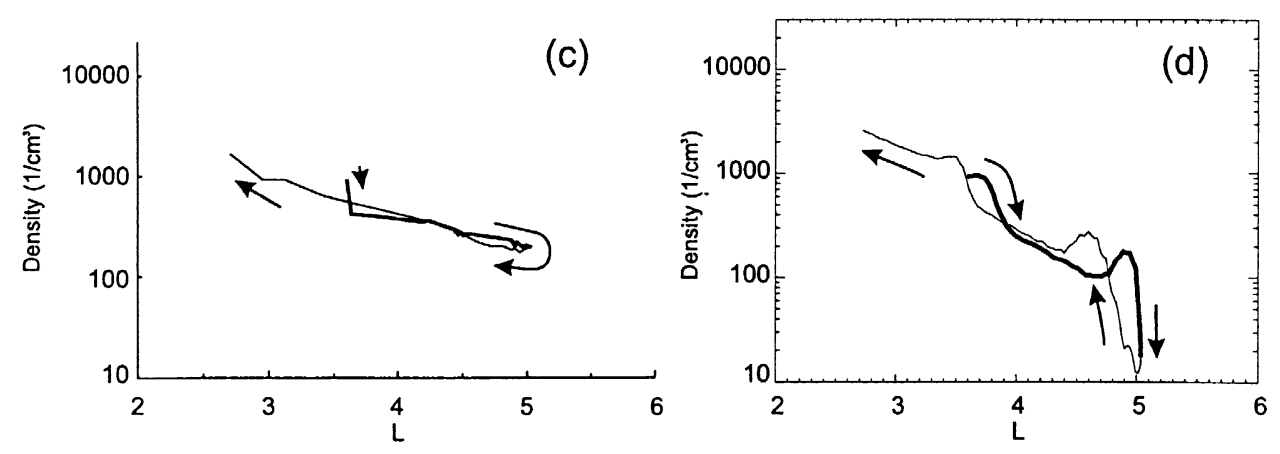

August 13, 1981 9:25-14:51 UT
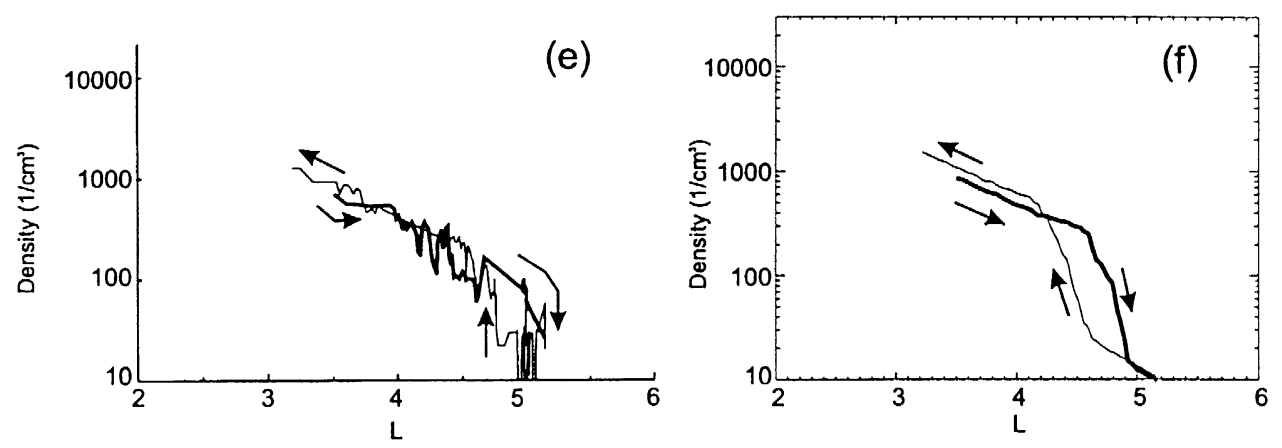

Fig. 4. Three days' radial profiles of thermal electron density observed by EXOS-B (left side) and profiles of thermal proton density calculated by our model (right side) along the trajectories of EXOS-B in the periods of 1304-1810 UT of August 11, 1981 (top panels), $1058-1632$ UT of August 12 (middle panels), 0925-1451 UT of August 13 (bottom panels). The thick lines represent the outbound paths.

electric field. The plasmapauses crossing by the satellite are $L=4.98$ and $L=4.34$ along the outbound and inbound paths, respectively. The difference between them is $\Delta L=0.64$ whereas the calculation gives $\Delta L=0.86$. Though the observed location of the plasmapause is slightly different, the changes in space and time coincide with the accuracy of about 34\%. The next orbit (August 12, 1981; middle panels of Fig. 4), EXOS-B did not encounter the plasmapause though the plasmasphere had shrunk last day. Therefore it seems as if the plasmasphere was refilled within a day. However it takes more than five days to refill the de- pleted plasmasphere up to the density of the order of 100 $\mathrm{cm}^{-3}$ at $L=5$ by our calculation. As mentioned above, the result of the numerical calculation shown in Fig. 3 suggests that EXOS-B moved together with a bulge (or a plasmatail) of the plasmasphere drifted from the noon-dusk quadrant by the corotation field. Therefore, EXOS-B did not encounter the plasmapause. The last orbit (August 13, 1981; bottom panels of Fig. 4), both observed and calculated profiles gradually decline with $L$ value. The absolute electron density given by the numerical calculation is approximately $900 \mathrm{~cm}^{-3}$ at $L=3.5$ and $300 \mathrm{~cm}^{-3}$ at $L=4.5$ (outbound), and these values are 


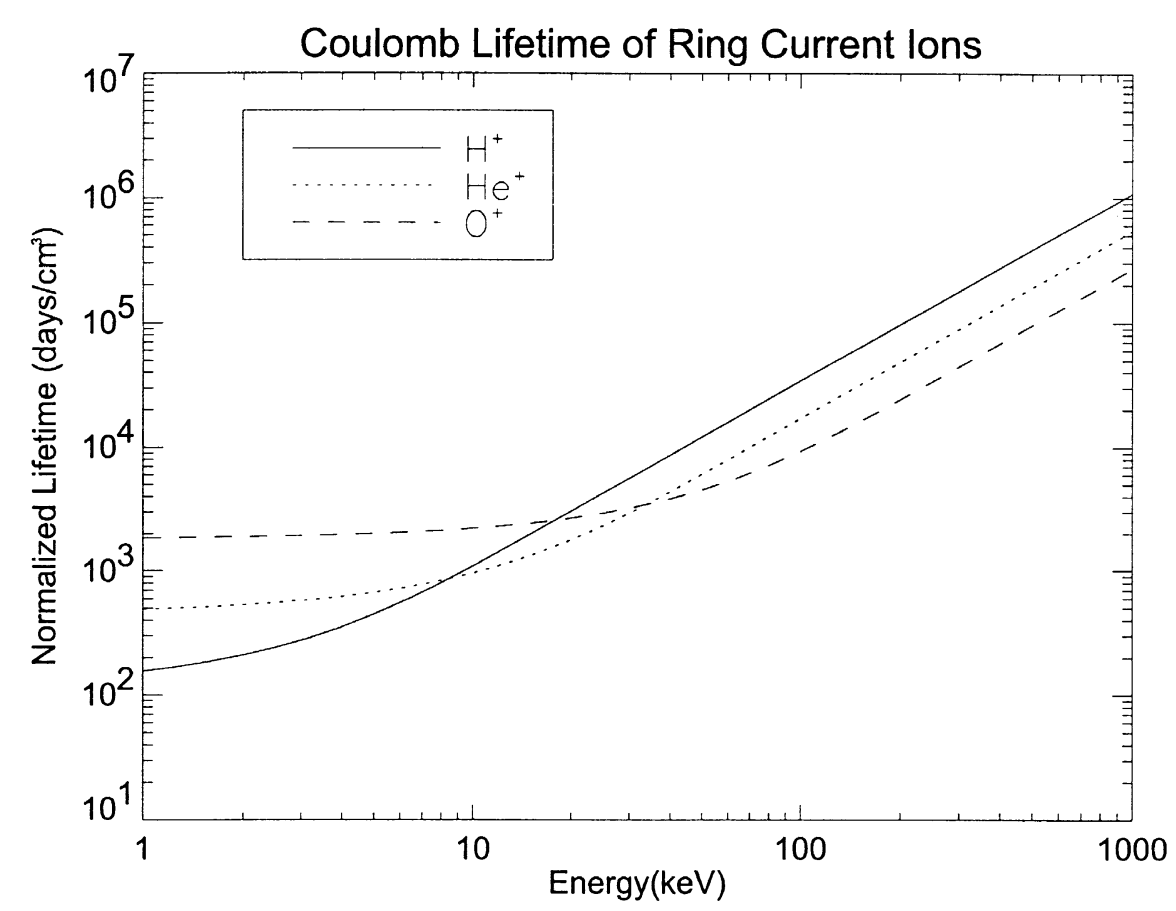

Fig. 5. The normalized Coulomb lifetimes of $\mathrm{H}^{+}$(solid line), $\mathrm{He}^{+}$(dotted line) and $\mathrm{O}^{+}$(dashed line) ions derived by the formulas of Fok et al. (1991).

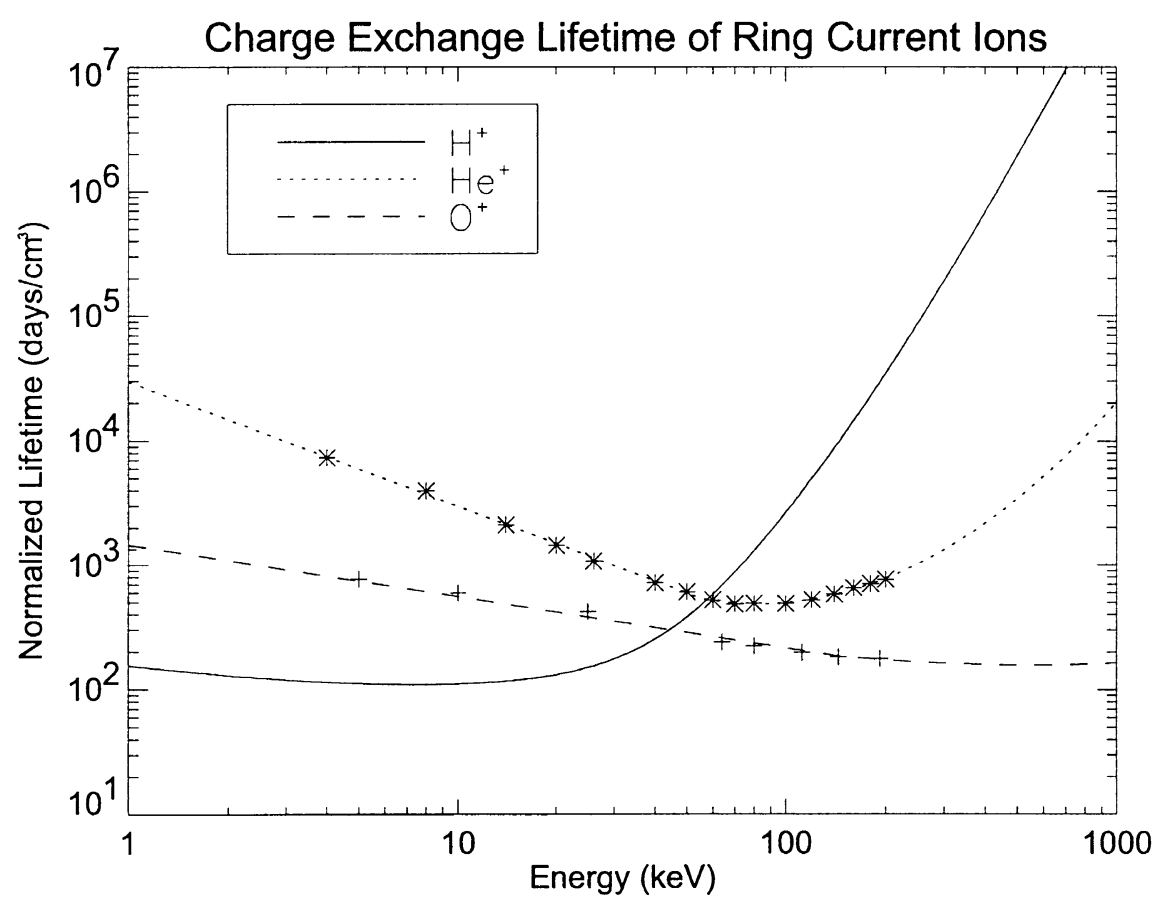

Fig. 6. The normalized charge exchange lifetimes of $\mathrm{H}^{+}$(solid line), $\mathrm{He}^{+}$(dotted line) and $\mathrm{O}^{+}$(dashed line) ions. The $\mathrm{H}^{+}$lifetime is given by Janev and Smith (1993), and the lifetimes of $\mathrm{He}^{+}$and $\mathrm{O}^{+}$are given by Smith and Bewtra (1978). The data points are the experimental value of Smith and Bewtra (1978), and we fit to the points.

approximately agreed with the satellite observation. Though the simulated profile (Fig. 4(f)) shows no fine structure, the location of the plasmapause segments, $4.6 \leq L \leq 4.9$ (outbound) and $4.1 \leq L \leq 4.6$ (inbound), are also in agreement with the satellite observation.

\section{Coulomb Lifetime of the Ring Current Ions}

The Coulomb decay lifetime of the ring current ions is calculated followed by a method of Fok et al. (1991). The Coulomb lifetime is calculated with the assumptions, that is, a distribution function of the plasmaspheric plasmas is 


\section{Lifetimes of $10 \mathrm{keV}$ ions}

\section{August 11, 1981 21:00UT}

\section{Coulomb Lifetime}
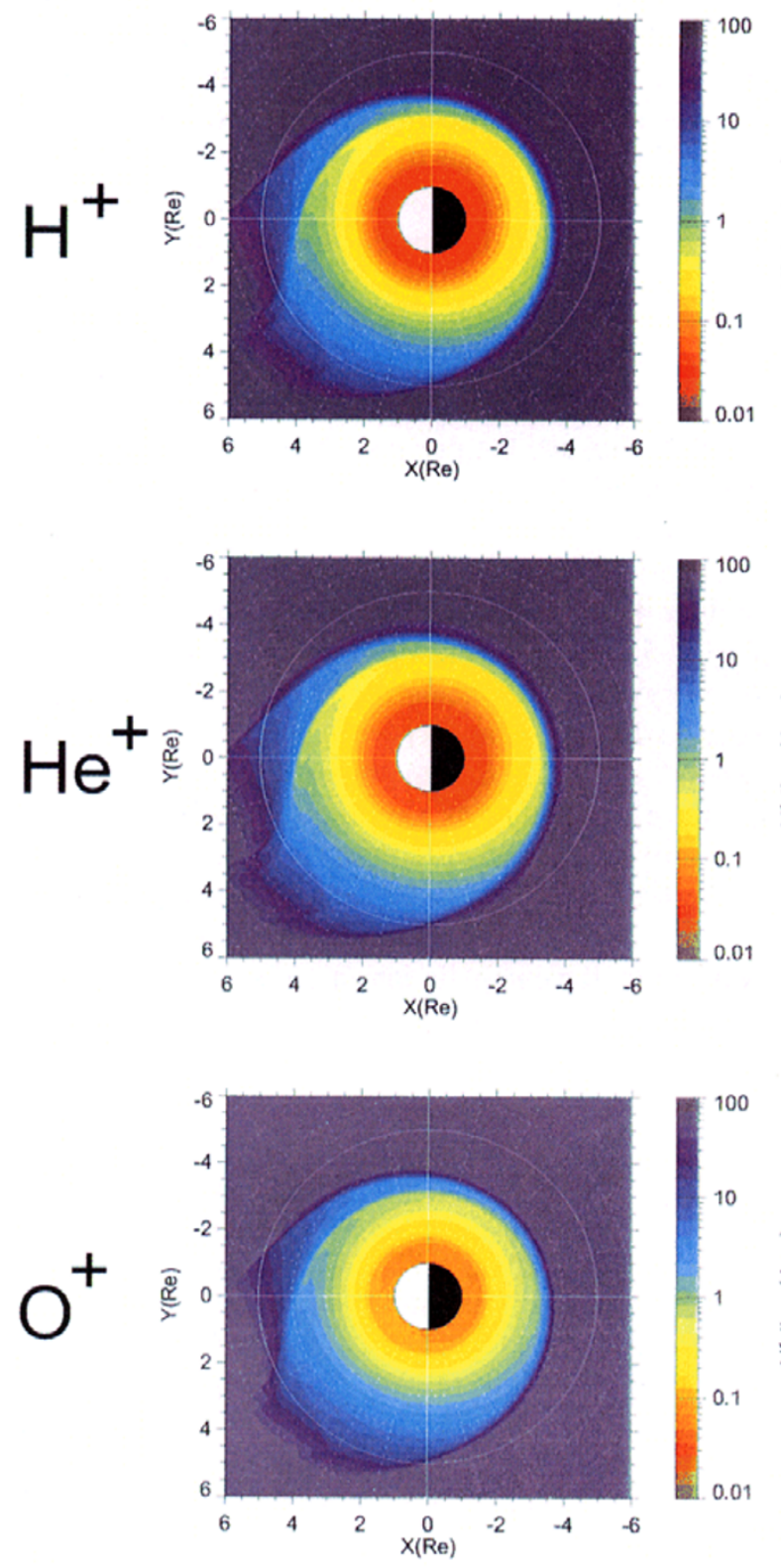

Charge Exchange Lifetime
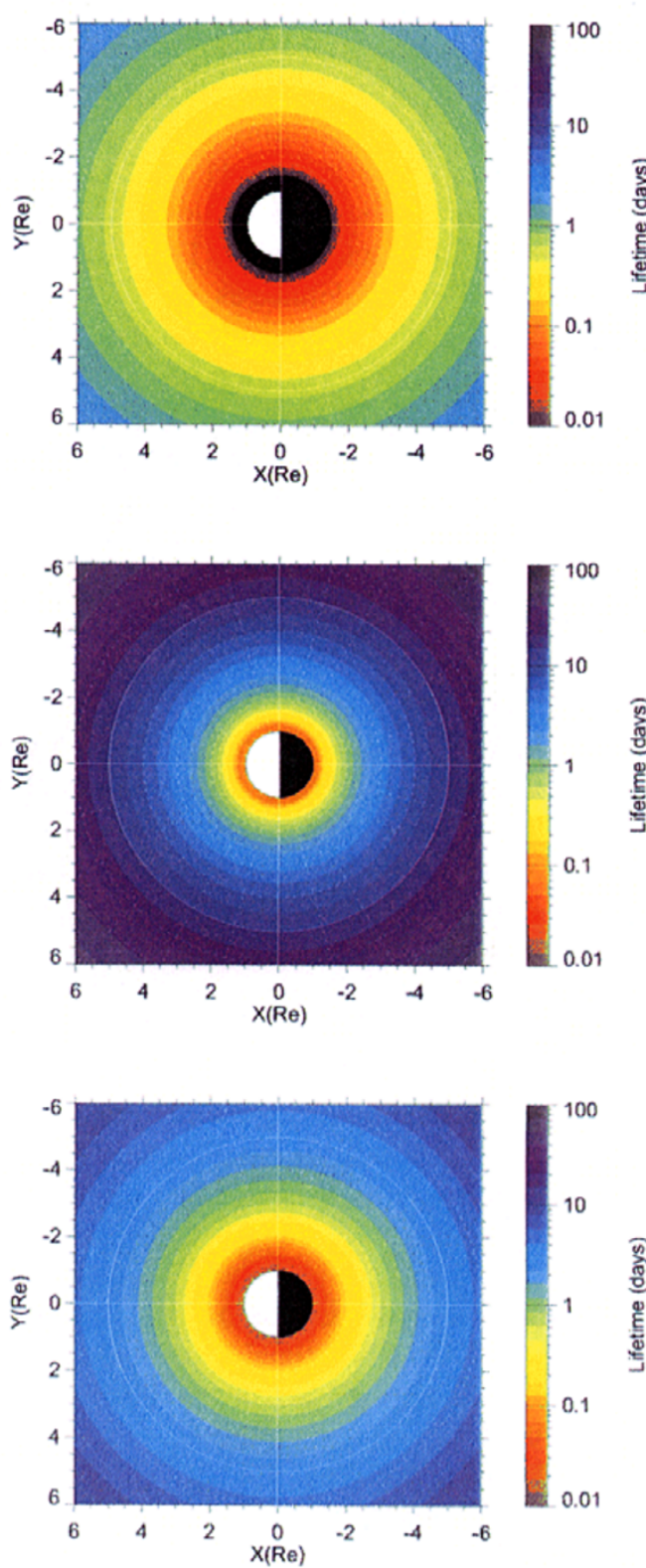

Fig. 7. The calculated lifetimes in the equatorial plane for $10 \mathrm{keV} \mathrm{H}^{+}$(top), $\mathrm{He}^{+}$(middle) and $\mathrm{O}^{+}$(bottom) ions due to Coulomb collision (left side) and charge exchange (right side) at 2100 UT of August 11, 1981.

Maxwellian with temperature of $1 \mathrm{eV}$. The normalized Coulomb lifetimes of $\mathrm{H}^{+}, \mathrm{He}^{+}$and $\mathrm{O}^{+}$ions as a function of energy are computed and plotted in Fig. 5. For example, if the ring current ions with energy of $1 \mathrm{keV}$ stay in the plasmasphere whose density is $100 \mathrm{~cm}^{-3}$, the lifetimes of $\mathrm{H}^{+}$, $\mathrm{He}^{+}$and $\mathrm{O}^{+}$ions are 1.6, 4.9 and 19 days, respectively. For the energy of $10 \mathrm{keV}$, the lifetimes are $11,9.6$ and 22 days, respectively.
The other major loss process of the ring current ions is the charge exchange. As described in Kistler et al. (1989), the dominant charge exchange loss of $\mathrm{H}^{+}, \mathrm{He}^{+}$and $\mathrm{O}^{+}$ions are due to the reactions of

$$
\begin{aligned}
\mathrm{H}^{+}+\mathrm{H} & \rightarrow \mathrm{H}+\mathrm{H}^{+}, \\
\mathrm{He}^{+}+\mathrm{H} & \rightarrow \mathrm{He}+\mathrm{H}^{+}, \\
\mathrm{O}^{+}+\mathrm{H} & \rightarrow \mathrm{O}+\mathrm{H}^{+} .
\end{aligned}
$$


The bounce-average charge exchange lifetime of the energetic ions $\tau_{\mathrm{ce}}$ is

$$
\tau_{\mathrm{ce}}=\frac{1}{n(\mathrm{H}) \sigma v} \cos ^{j} \lambda_{\mathrm{m}},
$$

where $n(\mathrm{H}), \sigma, v, \lambda_{\mathrm{m}}$ and $j$ are the number density of neutral hydrogen, the charge exchange cross section, the velocity of the ring current species, mirror latitude, and $j$ is given to be 3.5 (Smith and Bewtra, 1978). To obtain the number density of the neutral hydrogen, we use a Chamberlain model (Chamberlain, 1963) with a fitting parameter of Rairden et al. (1986). The cross section of the $\mathrm{H}^{+}$ions is given by Janev and Smith (1993), and the cross section of the $\mathrm{He}^{+}$and $\mathrm{O}^{+}$ ions are given by Smith and Bewtra (1978). The normalized charge exchange lifetime (defined as $\tau_{\mathrm{ce}} \times n(\mathrm{H})$ ) for $\mathrm{H}^{+}, \mathrm{He}^{+}$ and $\mathrm{O}^{+}$ions as a function of energy are plotted in Fig. 6 . For example, the charge exchange lifetimes of the ring current $\mathrm{H}^{+}, \mathrm{He}^{+}$and $\mathrm{O}^{+}$ions with energy of $1 \mathrm{keV}$ at the distance of $4 \mathrm{Re}$ from the center of the Earth are 0.57, 108, 5.3 days, respectively. For the energy of $10 \mathrm{keV}$, the lifetimes are 0.41 , 11 and 2.0 days, respectively.

The spatial variation of the calculated lifetimes for $10 \mathrm{keV}$ ions due to Coulomb collision and charge exchange is shown in Fig. 7. The Coulomb lifetimes are calculated by our model plasmasphere at 2100 UT of August 11, 1981 when the Dst index approximately reached at minimum in a weak magnetic storm. As indicated in Fig. 5, the Coulomb lifetimes of $10 \mathrm{keV}$ ions, $\mathrm{H}^{+}, \mathrm{He}^{+}$and $\mathrm{O}^{+}$, are similar to each other, and cannot be ignored in the plasmasphere. The energetic ions with energy of $10 \mathrm{keV}$ at $L=4$ have a Coulomb lifetime of a few days. As shown in Fig. 7, charge exchange loss is important for $10 \mathrm{keV}$ protons. For the $\mathrm{He}^{+}$ions of energy $10 \mathrm{keV}$, the charge exchange lifetime is longer than the Coulomb lifetime. On the contrary, for the $\mathrm{O}^{+}$ions of energy $10 \mathrm{keV}$, the charge exchange lifetime is comparable to the Coulomb lifetime in the plasmasphere. However, the charge exchange becomes the dominant loss process in the outer plasmasphere.

\section{Conclusions and Discussion}

We have developed the time-dependent plasmaspheric model derived from the total flux tube content model of Chen and Wolf (1972) with the assumptions; (1) the primary ion species in the plasmasphere is $\mathrm{H}^{+}$, (2) the main source and sink of the plasmaspheric $\mathrm{H}^{+}$ions are the charge exchange reaction in the conjugate ionospheres, and the production and loss regions are the altitude where the chemical equilibrium $\mathrm{H}^{+}$density is equal to $\mathrm{O}^{+}$density, (3) the distribution aligned with a field line is hydrostatic equilibrium and (4) the magnetic field is a dipole and the electric fields consist of the Volland-Stern type convection field and the corotation field. The accuracy of this model is examined by comparing with the EXOS-B satellite observations during the period of a weak magnetic storm from August 11-13, 1981. The calculated radial profiles of the electron density shown in Fig. 4 are in good agreement with the EXOS-B observation with respect to the absolute density, relative displacements of the plasmapause and the dynamical feature of the plasmasphere. By this plasmaspheric model, we could evaluate the spatial variation of the Coulomb collision lifetimes of the energetic ions. The Coulomb collision loss is comparable to the charge exchange loss for the $\mathrm{H}^{+}, \mathrm{He}^{+}$and $\mathrm{O}^{+}$ions with energies of below a few tens of $\mathrm{keV}$ in the plasmasphere as pointed out by Fok et al. (1991).

We have examined previously the basic loss effects of the newly injected ions due to Coulomb collision and charge exchange losses (Ebihara et al., 1997). Although Fok et al. (1995) investigated the decay of the ring current ions due to both losses by a three-dimensional kinetic model, we present preliminary results of the decay processes of the newly injected particles by tracing along their trajectories (a single particle code). In order to compare the change in the pressure due to the loss processes with the satellite observation, we trace the injected particles under a dipolar magnetic field and $K p$ dependent Volland-Stern type convection field by the bounce-average approximation described in Ejiri (1978), and we calculate the absolute differential flux and the plasma pressure. The methods to calculate the drift trajectory and the absolute flux and the pressure are described in Appendix A and $\mathrm{B}$, respectively.

Roeder et al. (1996) reported the results of the CRRES observation during the large magnetic storm which occurred on June $4-8,1991$; (1) the relative $\mathrm{O}^{+}$component of total at $L=3-5$ increased from $7 \%$ prior to the storm to $29 \%$ in the recovery phase, that means the relative ion composition never became dominated by oxygen, (2) the fastest decreasing ion was $\mathrm{O}^{+}$at $L=3-6$ in the recovery phase. The event was the large storm that has a complex main phase and two step recovery of $D s t$ as shown in the top panel of Fig. 8.

We tried to compare our model calculation with the observational results reported by Roeder et al. (1996). In our simulation, the energetic ions are injected from $L=8$ with longitudinal range of $21 \mathrm{~h} \leq \mathrm{MLT} \leq 3 \mathrm{~h}$ by the $K p$ dependent Volland-Stern type convection field during the period from 2300 UT on June 4 to 0000 UT on June 8. An inductive electric field in association with a substorm is not introduced here. The source distribution function is assumed to be an isotropic Maxwellian with a temperature $5 \mathrm{keV}$ and an ion number density $0.22 \mathrm{~cm}^{-3}$. These quantities are consistent with direct satellite observations in the plasmasheet as a source of an injection (Baumjohann and Paschmann, 1989; Thomsen et al., 1996). The composition ratio of $\mathrm{H}^{+}$, $\mathrm{He}^{+}$and $\mathrm{O}^{+}$ions as a source is assumed to be $0.8,0.05$ and 0.15 , respectively. Our model includes no radial diffusion, that is, the radial transport of the particles is caused by the convection.

The results of the calculation are shown in Figs. 8 and 9. The third and fourth panels of Fig. 8 are the radial profiles in the midnight meridian at 0000 UT on June 7, 1991 during the later recovery phase of the storm (denoted by (C) in the top panel). The third panel shows the loss rates of the plasma pressure. One can find that the Coulomb collision loss dominates the decrease of the $\mathrm{He}^{+}$and $\mathrm{O}^{+}$pressures, and the charge exchange loss dominates the decrease of $\mathrm{H}^{+}$ pressure. Since the core region of the plasmasphere $(\geq 100$ $\mathrm{cm}^{-3}$ ) shrank within $L \simeq 3$ at midnight during the main and the early recovery phases as shown in the second panel of Fig. 8, the Coulomb collision loss mainly affected the ions at $L \leq 3$. The bottom panel of Fig. 8 shows that the $\mathrm{H}^{+}$pressure decreased faster than $\mathrm{O}^{+}$and $\mathrm{He}^{+}$pressure in the inner 

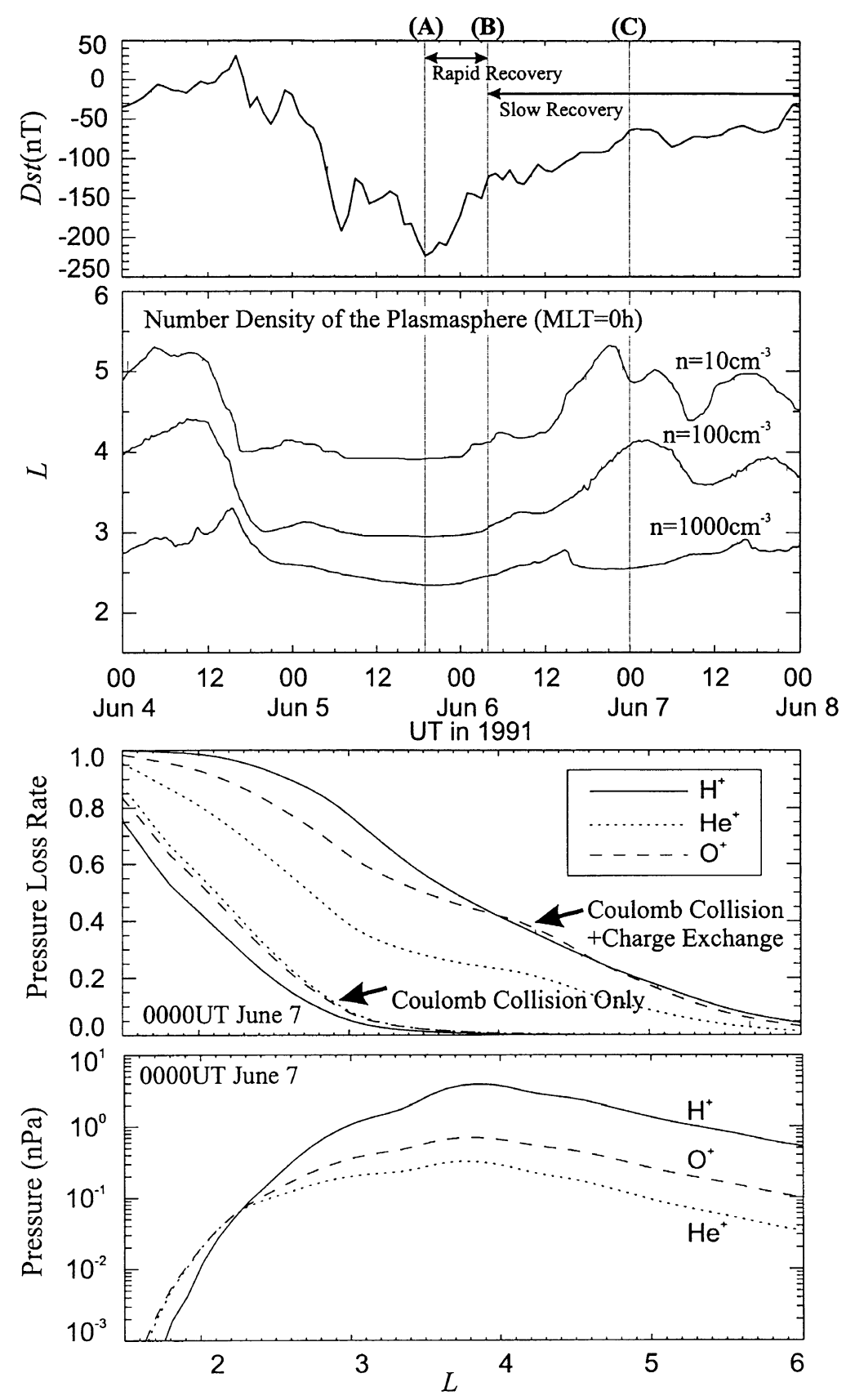

Fig. 8. The panels show from top to bottom; (top panel) the Dst index of the magnetic storm on June 4-8, 1991, (second panel) a contour showing plasmaspheric number densities of $10 \mathrm{~cm}^{-3}, 100 \mathrm{~cm}^{-3}$ and $1000 \mathrm{~cm}^{-3}$ in the midnight meridian, (third panel) the radial profile in the midnight meridian at 0000 UT on June 7, 1991; the loss rate due to Coulomb collision (lower left group) and loss rate due to Coulomb collision and charge exchange (upper right group), (bottom panel) also the radial profile in the midnight meridian of the plasma pressure of $\mathrm{H}^{+}, \mathrm{He}^{+}$and $\mathrm{O}^{+}$. The loss rate of 1.0 means that the pressure is completely lost.

magnetosphere due to the loss processes and that $\mathrm{H}^{+}$became a minor composition relative to $\mathrm{O}^{+}$and $\mathrm{He}^{+}$on the pressure at $L \leq 2.3$ at the later recovery phase. The absolute value of the calculated pressure at the peaks, however, is smaller than the observed pressure with a factor of 10 , the observed pressure around $L=3.5$ by Roeder et al. (1996) being $32 \mathrm{nPa}$, $8 \mathrm{nPa}$ and $13 \mathrm{nPa}$ for $\mathrm{H}^{+}, \mathrm{He}^{+}$and $\mathrm{O}^{+}$ions respectively. The difference of the pressure between the calculation and the observation is not a subject of matter in this paper because we discuss here the change in the relative composition ratio of the pressure.

The time evolution of the composition ratio of the pressure is shown in Fig. 9. At the beginning of the rapid recovery of this storm (1900 UT on June 5; labeled as (A)), the $\mathrm{O}^{+}$ is the major species at $L \leq 1.8$. There is no significant change in the pressure ratio during the rapid recovery phase (between 1900 UT on June 5 to 0400 UT on June 6). This result implies that the relatively shorter lifetime due to the charge exchange loss of $\mathrm{O}^{+}$ions is not a good explanation of the rapid initial recovery of $D s t$ in the two step recovery 
(A)

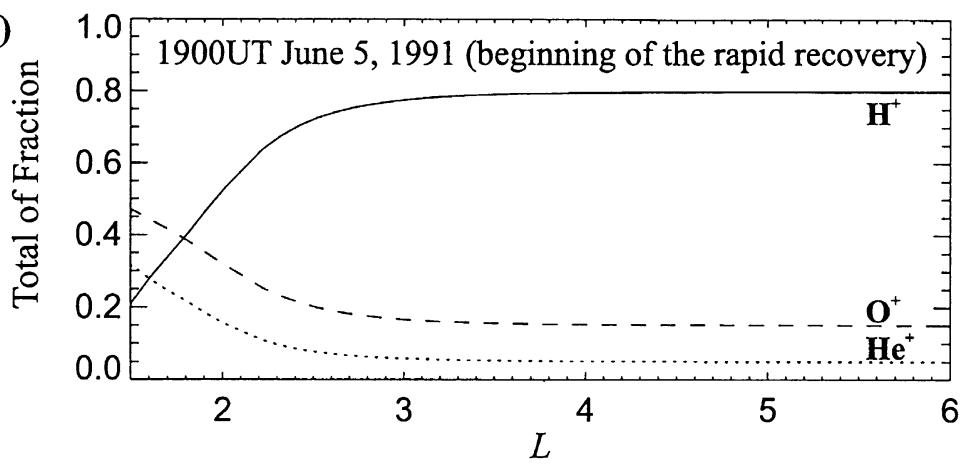

(B)

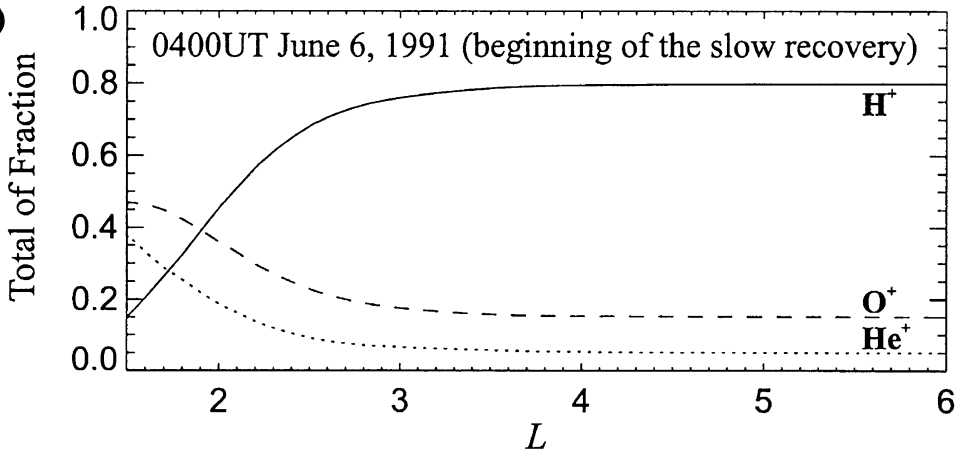

(C)

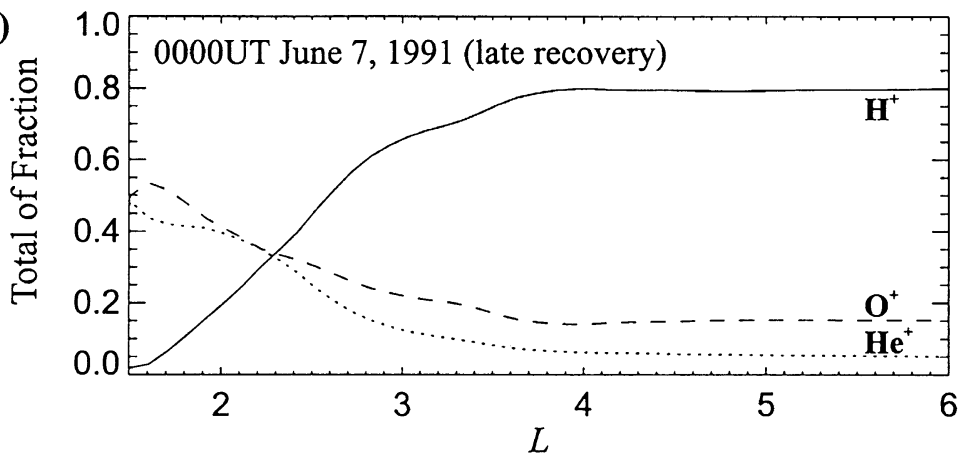

Fig. 9. The composition ratio of the $\mathrm{H}^{+}, \mathrm{He}^{+}$and $\mathrm{O}^{+}$pressure in the midnight meridian (A) at $1900 \mathrm{UT}$ on June 5, 1991 (beginning of the rapid recovery), (B) at 0400 UT on June 6, 1991 (end of the rapid recovery and beginning of the slow recovery) and (C) at 0000 UT on June 7, 1991 (late recovery).

for this particular storm. However, the CRRES observed the enhancement of the composition ratio of $\mathrm{O}^{+}$pressure up to $29 \%$ at $L=3-5$ in the recovery phase (Roeder et al., 1996). Namely, the enhancement of $\mathrm{O}^{+}$observed by the CRRES is considered to be arising from the change of the source composition in the plasmasheet. The change of the source composition is one of candidates for the two step recovery. In fact, ions originated from the ionosphere (mainly $\mathrm{O}^{+}$) obviously increase in the storm time plasmasheet (Peterson et al., 1981; Sharp et al., 1982; Lennartsson and Shelley, 1986; Daglis et al., 1994). The other candidate for the two step recovery is the convective outflow of newly injected particles (Takahashi et al., 1990).

Acknowledgments. The authors are grateful to Prof. Y. Ichikawa at the Institute of Space and Astronautical Science for his discussion on the recent charge exchange cross section of the proton.

\section{Appendix A. Drift Velocity of Energetic Particles}

We calculated the trapped particles injected from the nearEarth plasma sheet by the bounce-average approximation.
The bounce-average drift velocity $\left\langle\boldsymbol{V}_{s}\right\rangle$ is generally given by

$$
\begin{aligned}
\left\langle\boldsymbol{V}_{s}\right. & =\frac{\boldsymbol{E} \times \boldsymbol{B}}{B^{2}}+\frac{2}{\tau_{\mathrm{b}}} \int_{s_{\mathrm{m}}}^{s_{\mathrm{m}}^{\prime}} \frac{\overrightarrow{\boldsymbol{T}} \boldsymbol{V}_{s}}{v_{\|}} d s, \\
\boldsymbol{V}_{\bar{s}} & =\frac{m v_{\|}^{2}}{q B^{4}} \boldsymbol{B} \times(\boldsymbol{B} \cdot \nabla) \boldsymbol{B}+\frac{m v_{\perp}^{2}}{2 q B^{3}} \boldsymbol{B} \times \nabla B,
\end{aligned}
$$

where $\boldsymbol{E}, \boldsymbol{B}, \tau_{\mathrm{b}}, s_{\mathrm{m}},\left(s_{\mathrm{m}}^{\prime}\right), \overrightarrow{\boldsymbol{T}}, v_{\|}, v_{\perp}, d s, m$ and $q$ are an electric field, a magnetic field, a bounce period, conjugate mirror points, tensor for the coordinate conversion, a parallel velocity, a perpendicular velocity, a line element aligned with a field line, mass and charge, respectively (Roederer, 1970). The first and second terms on the right hand side of Eq. (A.2) represent the curvature drift and gradient- $\mathrm{B}$ drift velocities, respectively.

We can express the bounce-average drift velocity easily under the dipolar magnetic field as

$$
\left\langle\boldsymbol{V}_{s}\right\rangle=\frac{\boldsymbol{E} \times \boldsymbol{B}}{B^{2}}+\frac{W G\left(\alpha_{0}\right)}{q B^{3}} \boldsymbol{B} \times \nabla B,
$$

where $W, \alpha_{0}$ and $G\left(\alpha_{0}\right)$ are kinetic energy, an equatorial pitch 
angle and a function of a equatorial pitch angle, respectively. Ejiri (1978) gave an approximation formula of a function $G\left(\alpha_{0}\right)$ with an accuracy of within $0.1 \%$, and we used here this formula.

Each packet particle that has a number of real particles in a small phase space loses its number of particles with a time constant $\tau$ due to the charge exchange and Coulomb collision loss processes.

\section{Appendix B. Differential Flux and Pressure of En- ergetic Particles}

Following Cladis and Francis (1985), we derived a method to calculate the absolute differential flux of the trapped particles which include a number of real particles in the phase space. After an elapse time, a directional differential flux on the equatorial plane $j_{0}\left(L, \phi, W, y_{0}\right)$ where $\phi$ is MLT and $y_{0}=\sin \left(\alpha_{0}\right)$ is obtained by summing the all real particles that enter a phase space bin $\left(\Delta L, \Delta \phi, \Delta W, \Delta y_{0}\right)$ fixed on the equatorial plane as

$$
j_{0}\left(L, \phi, W, y_{0}\right)=\frac{\sum N_{i}}{2 \pi S \tau_{\mathrm{b}}\left(y_{0}\right) y \Delta y \Delta W},
$$

where $S, N_{i}$ and $\tau_{\mathrm{b}}$ are the area of a virtual detector on the equatorial plane, the real number of particles that the $i$-th packet particle carries and the bounce period of a particle, respectively. A flux at a given latitude $\lambda$ along a field line can be simply derived from the equatorial flux $j_{0}$ (Roederer, 1970) as

$$
j(L, \phi, \lambda, W, y)=j_{0}(L, \phi, W, h(\lambda) y),
$$

with

$$
h(\lambda) \equiv \frac{\cos ^{3} \lambda}{\left(1+3 \sin ^{2} \lambda\right)^{1 / 4}} .
$$

The plasma pressure is generally given by

$$
\begin{gathered}
P_{\mp}=\int \frac{1}{2} f(\boldsymbol{v}) m v^{2} \sin ^{2} \alpha d v, \\
P_{\mathbb{}}=\int f(v) m v^{2} \cos ^{2} \alpha d v,
\end{gathered}
$$

where $f, v$ are a velocity distribution function and a velocity, respectively. We can rewrite Eqs. (B.4) and (B.5) as

$$
\begin{aligned}
& P_{\digamma} \pi \sqrt{2 m} \int_{\alpha} \int_{W} j_{0}(L, \phi, W, h(\lambda) \sin \alpha) \\
& \sqrt{W} \sin ^{3} \alpha d \alpha d W \\
& P_{\mathbb{Z} 2 \pi} \sqrt{2 m} \int_{\alpha} \int_{W} j_{0}(L, \phi, W, h(\lambda) \sin \alpha) \\
& \cdot \sqrt{W} \cos ^{2} \alpha \sin \alpha d \alpha d W .
\end{aligned}
$$

\section{References}

Banks, P. M. and G. Kockarts, Aeronomy, Part B, 355 pp., Academic Press, New York, 1973.

Baumjohann, W. and G. Paschmann, Average plasma properties in the central plasmasheet, J. Geophys. Res., 94, 6597-6606, 1989.

Bilitza, D., International reference ionosphere: Recent developments, Radio Sci., 21, 343-346, 1986.

Brice, N. M., Bulk motion of the magnetosphere, J. Geophys. Res., 72, 5193-5211, 1967.

Carpenter, D. L., Whistler studies of the plasmapause in the magnetosphere, J. Geophys. Res., 71, 693-709, 1966.
Carpenter, D. L. and R. R. Anderson, An ISEE/Whistler model of equatorial electron density in the magnetosphere, J. Geophys. Res., 97, 1097-1108, 1992.

Chamberlain, J. W., Planetary coronae and atmospheric evaporation, Planet. Space Sci., 11, 901-960, 1963.

Chappell, C. R., K. K. Harris, and G. W. Sharp, The morphology of the bulge region of the plasmasphere, J. Geophys. Res., 75, 3848-3861, 1970.

Chen, A. J. and R. A. Wolf, Effects on the plasmasphere of a time-varying convection electric field, Planet. Space Sci., 20, 483-509, 1972.

Cladis, J. B. and W. E. Francis, The polar ionosphere as a source of the storm time ring current, J. Geophys. Res., 90, 3465-3473, 1985.

Daglis, I. A., S. Livi, E. T. Sarris, and B. Wilken, Energy density of ionospheric and solar wind origin ions in the near-Earth magnetotail during substorms, J. Geophys. Res., 99, 5691-5703, 1994.

Dessler, A. J. and E. N. Parker, Hydromagnetic theory of geomagnetic storms, J. Geophys. Res., 64, 2239-2252, 1959.

Ebihara, Y., H. Miyaoka, F. Tohyama, and M. Ejiri, Loss effects for energetic protons associated with a magnetic storm in the inner magnetosphere, Proc. NIPR Symp. Upper Atmos. Phys., 10, 16-28, 1997.

Ejiri, M., Trajectory traces of charged particles in the magnetosphere, $J$. Geophys. Res., 83, 4798-4810, 1978.

Ejiri, M., K. Tsuruda, Y. Watanabe, A. Nishida, and T. Obayashi, Impedance and electric field observations in the magnetosphere with satellite JIKIKEN(EXOS-B), J. Geomag. Geoelectr., 33, 101-110, 1981.

Fok, M.-C., J. U. Kozyra, A. F. Nagy, and T. E. Cravens, Lifetime of ring current particles due to Coulomb collisions in the plasmasphere, J. Geophys. Res., 96, 7861-7867, 1991.

Fok, M.-C., T. E. Moore, J. U. Kozyra, G. C. Ho, and D. C. Hamilton, Threedimensional ring current decay model, J. Geophys. Res., 100, 9619-9632, 1995.

Gallagher, D. L., P. D. Craven, R. H. Comfort, and T. E. Moore, On the azimuthal variation of core plasma in the equatorial magnetosphere, $J$. Geophys. Res., 100, 23597-23605, 1995.

Grebowsky, J. M. and A. J. Chen, Effects of convection electric field on the distribution of ring current type protons, Planet. Space Sci., 23, 10451052,1975 .

Grebowsky, J. M., Y. Tulunay, and A. J. Chen, Temporal variations in the dawn and dusk midlatitude trough and plasmapause, Planet. Space Sci., 22, 1089-1099, 1974.

Guiter, S. M., T. I. Gombosi, and C. E. Rasmussen, Two-stream modeling of plasmaspheric refilling, J. Geophys. Res., 100, 9519-9526, 1995.

Hedin, A. E., MSIS-86 thermospheric model, J. Geophys. Res., 92, 46494662, 1987.

Hedin, A. E., Extension of the MSIS thermosphere model into the middle and lower atmosphere, J. Geophys. Res., 96, 1159-1172, 1991.

Horwitz, J. L., R. H. Comfort, and C. R. Chappell, A statistical characterization of plasmasphere density structure and boundary locations, $J$. Geophys. Res., 95, 7937-7947, 1990.

Janev, R. K. and J. J. Smith, Cross sections for collision processes of hydrogen atoms with electrons, protons, and multipli-charged ions, Atomic and Plasma-Material Interaction Data for Fusion, IAEA, 4, 78-79, 1993.

Khazanov, G. V., M. A. Koen, Y. V. Konikov, and I. M. Sidorov, Simulation of ionosphere-plasmasphere coupling taking into account ion inertia and temperature anisotropy, Planet. Space Sci., 32, 585-598, 1984.

Kistler, L. M., F. M. Ipavich, D. C. Hamilton, G. Gloeckler, B. Wilken, G. Kremser, and W. Studemann, Energy spectra of the major ion species in the ring current during geomagnetic storms, J. Geophys. Res., 94, 35793599, 1989

Lennartsson, W. and E. G. Shelley, Survey of 0.1- to 16-keV/e plasma sheet ion composition, J. Geophys. Res., 91, 3061-3076, 1986.

Li, W., J. J. Sojka, and W. J. Raitt, A study of plasmaspheric density distributions for diffusive equilibrium conditions, Planet. Space Sci., 31, 1315-1327, 1983.

Liemohn, H., The lifetime of radiation belt protons with energies between $1 \mathrm{keV}$ and $1 \mathrm{MeV}$, J. Geophys. Res., 66, 3593-3595, 1961.

Lin, J., J. L. Horwitz, G. R. Wilson, C. W. Ho, and D. G. Brown, A semikinetic model for early stage plasmasphere refilling 2 . Effects of waveparticle interactions, J. Geophys. Res., 97, 1121-1134, 1992.

Marubashi, K. and J. M. Grebowsky, A model study of diurnal behavior of the ionosphere and the protonosphere coupling, J. Geophys. Res., 81, 1700-1706, 1976.

Maynard, N. C. and A. J. Chen, Isolated cold plasma regions: Observations and their relation to possible production mechanisms, J. Geophys. Res., 80, 1009-1013, 1975.

Mayr, H. G., J. M. Grebowsky, and H. A. Taylor, Jr., Study of the thermal 
plasma on closed field lines outside the plasmasphere, Planet. Space Sci., 18, 1123-1135, 1970.

Moffett, R. J. and J. A. Murphy, Coupling between the F-region and protonosphere: Numerical solution of the time-dependent equations, Planet. Space Sci., 21, 43-52, 1973

Moldwin, M. B., M. F. Thomsen, S. J. Bame, D. McComas, and G. D. Reeves, The fine-scale structure of the outer plasmasphere, J. Geophys. Res., 100, 8021-8029, 1995.

Nishida, A., Formation of plasmapause, or magnetospheric plasma knee, by the combined action of magnetospheric convection and plasma escape from the tail, J. Geophys. Res., 71, 5669-5679, 1966.

Olsen, R. C., S. D. Shawhan, D. L. Gallagher, J. L. Green, C. R. Chappell, and R. R. Anderson, Plasma observations at the Earth's magnetic equator, J. Geophys. Res., 92, 2385-2407, 1987.

Peterson, W. K., R. D. Sharp, E. G. Shelley, and R. G. Johnson, Energic ion composition of the plasmasheet, J. Geophys. Res., 86, 761-767, 1981.

Rairden, R. L., L. A. Frank, and J. D. Craven, Geocoronal imaging with Dynamic Explorer, J. Geophys. Res., 91, 13613-13630, 1986.

Raitt, W. J., R. W. Schunk, and P. M. Banks, A comparison of the temperature and density structure in high and low speed thermal proton flows, Planet. Space Sci., 23, 1103-1117, 1975.

Rasmussen, C. E., S. M. Guiter, and S. G. Thomas, A two-dimensional model of the plasmasphere: refilling time constants, Planet. Space Sci., 41, 35-43, 1993.

Roeder, J. L., J. F. Fennell, M. W. Chen, M. Grande, S. Livi, and M. Schulz, CRRES observations of stormtime ring current ion composition, AIP Conf. Proc., Workshop on the Earth's Trapped Particle Environment, No. 383, 131-135, 1996.

Roederer, J. G., Dynamics of Geomagnetically Trapped Radiation, 166 pp.,
Springer-Verlag, Berlin Heidelberg, 1970.

Sharp, R. D., W. Lennartsson, W. K. Peterson, and E. G. Shelley, The origins of the plasma in the distant plasma sheet, J. Geophys. Res., 87, 10420 10424, 1982.

Singh, N. and C. B. Chan, Effects of equatorially trapped ions on refilling of the plasmasphere, J. Geophys. Res., 97, 1167-1179, 1992.

Smith, P. H. and N. K. Bewtra, Charge exchange lifetimes for ring current ions, Space Sci. Rev., 22, 301-318, 1978.

Smith, P. H., R. A. Hoffman, and T. A. Fritz, Ring current proton decay by charge exchange, J. Geophys. Res., 81, 2701-2708, 1976.

Stern, D. P., The motion of a proton in the equatorial magnetosphere, $J$. Geophys. Res., 80, 595-599, 1975.

Takahashi, S., T. Iyemori, and M. Takeda, A simulation of the storm-time ring current, Planet. Space Sci., 38, 1133-1141, 1990.

Thomsen, M. F., J. E. Borovsky, D. J. McComas, and M. B. Moldwin, Observations of the Earth's plasmasheet at geosynchronous orbit, AIP Conf. Proc., Workshop on the Earth's Trapped Particle Environment, No. 383, 25-31, 1996.

Volland, H., A semiempirical model of large-scale magnetospheric electric fields, J. Geophys. Res., 78, 171-180, 1973.

Wentworth, R. C., W. M. MacDonald, and S. F. Singer, Lifetimes of trapped radiation belt particles determined by Coulomb scattering, Phys. Fluids, 2, 499-509, 1959.

Wilson, G. R., J. L. Horwitz, and J. Lin, A semikinetic model for early stage plasmasphere refilling 1. Effects of Coulomb collisions, J. Geophys. Res., 97, 1109-1119, 1992.

Y. Ebihara (e-mail: ebihara@nipr.ac.jp), M. Ejiri, and H. Miyaoka 